\title{
Biased usage of synovial immunoglobulin heavy chain variable region 4 by the anti-glucose-6-phosphate isomerase antibody in patients with rheumatoid arthritis
}

\author{
TAICHI HAYASHI ${ }^{1}$, ISAO MATSUMOTO ${ }^{1,2}$, TAKANORI YASUKOCHI $^{1,2}$, MIZUKO MAMURA $^{1}$, \\ DAISUKE GOTO $^{1}$, SATOSHI ITO ${ }^{1}$, AKITO TSUTSUMI ${ }^{1}$ and TAKAYUKI SUMIDA $^{1}$
}

\begin{abstract}
${ }^{1}$ Division of Clinical Immunology, Major of Advanced Biomedical Applications, Graduate School of Comprehensive Human Science, University of Tsukuba, 1-1-1 Tennodai, Tsukuba, Ibaraki 305-8575; ${ }^{2}$ PRESTO, Japan Science and Technology Agency, 4-1-8 Honcho Kawaguchi, Saitama, Japan
\end{abstract}

Received March 12, 2007; Accepted April 16, 2007

\begin{abstract}
Rheumatoid arthritis (RA) is the most common inflammatory arthritis, characterized by marked infiltration of mononuclear cells including B cells into the inflamed synovium. Anti-glucose-6-phosphate isomerase (GPI) antibody $(\mathrm{Ab})$ is an arthritogenic $\mathrm{Ab}$ in $\mathrm{K} / \mathrm{BxN} \mathrm{T}$ cell receptor transgenic mice, and is also present in some patients with RA. To characterize synovial B cells from anti-GPI Ab-positive RA, synovial immunoglobulin (Ig) heavy chain variable regions (VH) were compared with those of negative individuals. Synovial tissues were obtained from six RA patients (three anti-GPI Ab-positive and three anti-GPI Ab-negative). Ig-VH genes were amplified by PCR using family-specific primers and were subsequently sequenced. In synovial B cells from anti-GPI Ab-positive RA patients, VH4 and JH4 were predominantly expressed $(\mathrm{p}<0.0001)$. The immunoglobulin heavy chain complementarity-determining region 3 (IgH-CDR3) length in the synovium of anti-GPI Ab-positive individuals was shorter than that in anti-GPI Ab-negative individuals $(p=0.0005)$. In addition, the IgH-CDR3 of anti-GPI Ab-positive patients was rich in basic-ionized amino acids (arginine, histidine, and lysine) near their central position, suggesting a high affinity. Our results support the notion that Ig-VH4 B cells in RA synovium with anti-GPI Ab are affinity-matured
\end{abstract}

Correspondence to: Dr Isao Matsumoto, Clinical immunology, University of Tsukuba, 1-1-1 Tennodai, Tsukuba, Ibaraki 305-8575, Japan

E-mail: ismatsu@md.tsukuba.ac.jp

Abbreviations: -, negative; +, positive; DH, heavy chain diversity regions; FR, framework region; GPI, glucose-6-phosphate isomerase; IgH-CDR3, immunoglobulin heavy chain complementarity determining region 3; JH, heavy chain joining regions; RA, rheumatoid arthritis; SLE, systemic lupus erythematosus; VH, heavy chain variable regions

Key words: autoantibodies, rheumatoid arthritis, glucose-6-phosphate isomerase, B cells, synovium and that anti-GPI Ab might be associated with the skewed IgH-CDR3.

\section{Introduction}

Rheumatoid arthritis (RA) is an inflammatory condition characterized by systemic polyarthritis with bone erosion that affects the peripheral joints. The etiology of RA remains unclear with immunological processes including $\mathrm{T}$ cell-B cell interactions, innate immunity, and cytokine activity being implicated (1). In RA, the synovium contains many infiltrating mononuclear cells including B cells at various developmental stages, T cells, and macrophages (2).

Treatments for RA include agents that target cytokines such as tumor necrosis factor. These inflammation-neutralizing approaches have achieved good results in reducing not only joint inflammation but also bone erosion. More recently, depletion of B cells from RA patients has also produced significant therapeutic benefits in several clinical trials $(3,4)$. $\mathrm{B}$ cells are thought to be crucial in the pathogenesis of RA, through the production of autoantibodies, antigen presentation, cytokine secretion, and costimulatory signaling. In fact, autoantibodies including rheumatoid factor and anti-cyclic citrullinated peptide antibody $(\mathrm{Ab})$ have been used as diagnostic markers of RA. However, most such autoantibodies are not pathogenic. In contrast, anti-glucose-6-phosphate isomerase (GPI) $\mathrm{Ab}$ is a candidate arthritogenic $\mathrm{Ab}$, identified using the $\mathrm{K} / \mathrm{BxN}$ arthritis model (5-7). In this model, disease development was initiated by the activation of $\mathrm{B}$ and $\mathrm{T}$ cells. In addition, B cell-deficient mice do not develop arthritis (8). Anti-GPI Ab is also detected in some RA patients, with the reported prevalence varying from $5 \%$ to $64 \%$ of RA patients (9-12). This $\mathrm{Ab}$ is associated with extra-articular manifestations, and its titer correlates with the disease activity $(10,13)$. Moreover, anti-GPI Ab is also detected in the inflamed synovium of RA (14-16). Thus, B cells and autoantibodies appear to play important roles in the pathogenesis of RA in anti-GPI Ab-positive patients, especially in the inflamed joint synovium.

Immunoglobulin molecules are composed of two heavy chains and two light chains, and are characterized by the 
Table I. Profile of participating patients (RA1-RA6).

\begin{tabular}{|c|c|c|c|c|c|c|c|c|}
\hline & \multirow{2}{*}{$\begin{array}{c}\text { Age } \\
\text { (years) }\end{array}$} & \multirow[t]{2}{*}{ Sex } & \multirow{2}{*}{$\begin{array}{l}\text { Disease duration } \\
\quad \text { (years) }\end{array}$} & \multicolumn{2}{|c|}{ Anti-GPI Ab (OD 405 nm) } & \multirow{2}{*}{$\begin{array}{c}\mathrm{RF} \\
(\mathrm{IU} / \mathrm{ml})\end{array}$} & \multirow{2}{*}{$\begin{array}{l}\text { CRP } \\
(\mathrm{mg} / \mathrm{dl})\end{array}$} & \multirow{2}{*}{$\begin{array}{l}\text { MMP-3 } \\
(\mathrm{ng} / \mathrm{ml})\end{array}$} \\
\hline & & & & Human & Rabbit & & & \\
\hline RA1 & 66 & $\mathrm{~F}$ & 20 & 1.78 & 3.14 & 156 & 0.57 & 363 \\
\hline RA2 & 70 & $\mathrm{~F}$ & 25 & 2.60 & 3.47 & 149 & 0.42 & 275 \\
\hline RA3 & 69 & $\mathrm{~F}$ & 16 & 2.43 & 2.55 & 516 & 3.55 & 295 \\
\hline RA4 & 64 & $\mathrm{~F}$ & 33 & 0.72 & 0.20 & 78 & 0.05 & ND \\
\hline RA5 & 72 & $\mathrm{~F}$ & 22 & 0.62 & 0.05 & 119 & 0.74 & 215 \\
\hline RA6 & 74 & $\mathrm{~F}$ & 20 & 0.40 & 0.36 & 5 & 0.56 & 256 \\
\hline
\end{tabular}

All synovia were from the knees of female patients with rheumatoid arthritis (RA). The cutoff OD was calculated from ELISA reaction of 145 healthy Japanese donors, the mean value + two standard deviation was 1.32 to human recombinant GPI, and 0.94 to rabbit native GPI. Double-positive populations were considered anti-GPI Ab-positive. RA1-3 were anti-glucose-6-phosphate isomerase (GPI) Ab (+), and RA4-6 were anti-GPI Ab (-). Apart from anti-GPI Ab, all other parameters were matched to the utmost extent. GPI, glucose-6-phosphate isomerase; RF, rheumatic factor; CRP, C-reactive protein; MMP-3, matrix metalloproteinase-3; ND, not done.

antigen-binding site sequence and Fc isotype. The antigenbinding site is made up of variable regions and rearranged complementarity-determining regions (CDR) that determine the individual immune properties of any given $\mathrm{B}$ cell. The immunoglobulin heavy chain CDR3 (IgH-CDR3) is the most crucial site for antigen binding. H-CDR3 is rearranged by one of 44 variable segments ( $\mathrm{VH})$, one or more of 25 diversity segments (DH), and one of six joining segments (JH) (17). In addition, $\mathrm{VH}$ genes can be divided into seven sub-families (VH1 to VH7), with overrepresentation of VH4 genes reported in some autoimmune conditions (18). Negative selection of VH4 repertoires is implemented in healthy individuals to avoid autoimmunity $(19,20)$. On the other hand, in RA patients, synovial B cells, especially plasma cells, are also biased to express the VH4 repertoire $(21,22)$, though this was negated in another report (23), and antigen-driven affinity maturation has been reported (23-26).

The present study defined the synovial B cell characteristics of anti-GPI Ab-positive (+) RA patients by analyzing VH regions of synovial $\mathrm{B}$ cells from anti-GPI $\mathrm{Ab}(+)$ and negative (-) RA patients and compared the rearranged IgH-CDR3 sequences of their VH4 genes. Twenty-seven IgH-VH4 gene sequences from anti-GPI Ab (+) RA patients were compared with thirty-six VH4 gene sequences from anti-GPI Ab (-) patients. In both groups, over $70 \%$ of VH4 clones seemed to be undergoing antigen-driven maturation, as evidenced by an $\mathrm{R} / \mathrm{S}$ ratio of $>3$ in the $\mathrm{CDR}$ and less in the framework region (FR). However, the JH4 gene was more predominant in the synovium of anti-GPI Ab (+) RA patients compared to anti-GPI $\mathrm{Ab}(-)$ cases and the lengths of their IgH-CDRs were shorter. In addition, there was no biased usage of VH4 subfamily genes. Together, these findings suggest that B cells from anti-GPI $\mathrm{Ab}(+) \mathrm{RA}$ synovium are affinity-matured by antigens, with frequent usage of VH4-JH4.

\section{Materials and methods}

Subjects. Synovial tissues were obtained from six patients [three were anti-GPI $\mathrm{Ab}(+)$ and three were anti-GPI $\mathrm{Ab}(-)]$ who
Table II. Specific primers for each VH family.

\begin{tabular}{cl}
\hline Internal & \\
VH1 & 5'-TCACCATGGACTGCACCTGGA-3' \\
VH2 & 5'-CCATGGACACACTTTGCTCCAC-3' \\
VH3 & 5'-TCACCATGGAGTTTGGGCTGAGC-3' \\
VH4 & 5'-AGAACATGAAACACCTGTGGTTCTT-3' \\
VH5 & 5'-ATGGGGTCAACCGCCATCCT-3' \\
VH6 & 5'-ACAATGTCTGTCTCCTTCCTCAT-3' \\
C $\gamma$ & 5'-CATCGGTCTTCCCCCTGGC-3' \\
External & \\
VH1 & 5'-GAGAAAACCCTGTGAGCACAGCT-3' \\
VH2 & 5'-AGTGACTCCTGTGCCCCAC-3' \\
VH3 & 5'-GATCAGCACTGAACACAGAGGAC-3' \\
VH4 & 5'-GTCATGGACCTCCTGCACAAG-3' \\
VH5 & 5'-AGGGCTTCATTTTCTGTCCTCCAC-3' \\
VH6 & 5'-GGGGCAGTCACCAGAGCTC-3' \\
C $\gamma$ & 5'-GAGCACCTCCGAGAGCACA-3' \\
\hline
\end{tabular}

Sequences of primers used in nested PCR to detect immunoglobulin heavy chain variable segment (VH) 1-6 family genes.

satisfied the American College of Rheumatology criteria for RA (1987) (27) (Table I). For selecting anti-GPI Ab-positive patients, enzyme linked immunosorbent assay (ELISA) was performed using two different sources of GPI; a recombinant human GPI (huGPI), and a rabbit muscle GPI (raGPI) (Sigma Chemical Co., St. Louis, MO) which had been described in detail previously (12). Informed consent for using synovial tissues and blood sampling was obtained from all patients at the time of the relevant procedure.

cDNA synthesis. Synovial tissues were minced and homogenized in Isogen (Nippon Gene, Tokyo, Japan) and extracted with chloroform. RNA was precipitated with isopropanol, 


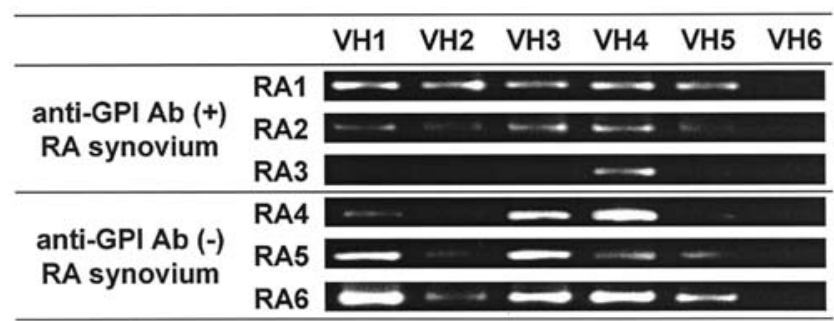

Figure 1. Nested PCR for immunoglobulin heavy chain variable segment (VH) subfamily of rheumatoid synovium. Amplification of $\mathrm{VH}$ genes by nested PCR was conducted as shown. Only VH4 genes were amplified in all individuals. VH1 to VH5 were amplified in all cases except RA3.

resuspended in $10 \mathrm{mM}$ Tris $\cdot \mathrm{HCl}(\mathrm{pH} 8.0)$ and $1 \mathrm{mM}$ EDTA. RevertAid first-strand cDNA synthesis kits (Fermentas, Ontario, Canada) were used for reverse transcription, in accordance with the manufacturer's instructions. Total RNA $(5 \mu \mathrm{g})$ was used for this reaction.

Amplification of VH genes. Rearranged immunoglobulin VH genes were amplified by PCR. Nested PCR was conducted to obtain sufficient PCR product for electrophoresis. To avoid sequence errors, the first PCR products were subjected to sequencing. Specific oligonucleotides for six different $\mathrm{VH}$ families (VH1 to VH6) were used as 5'-primers. Oligonucleotide corresponding to the known $\mathrm{C} \gamma$ was used as a 3'primer. For the second PCR, an additional set of primers using the internal sequences was prepared (Table II). One microliter of template was added to $24 \mu \mathrm{l}$ of a PCR master mix, containing 1.25 U rTaq DNA polymerase (Takara Bio Inc, Shiga, Japan), $2.5 \mu \mathrm{l}$ of manufacturer's 10X PCR buffer, $2 \mu \mathrm{l}$ of $2.5 \mathrm{mM}$ dNTPs, and $2.5 \mu \mathrm{l}$ of each $10-\mu \mathrm{M}$ primer. The first round of PCR was performed for 25 cycles at $95^{\circ} \mathrm{C}$ for $30 \mathrm{sec}$ to denature, 54 or $56^{\circ} \mathrm{C}$ for $30 \mathrm{sec}$ to anneal (annealing for $\mathrm{VH} 1$, $\mathrm{VH} 2, \mathrm{VH} 3, \mathrm{VH} 5$ at $56^{\circ} \mathrm{C}$, and for VH4, VH6 at $54^{\circ} \mathrm{C}$ ), $72^{\circ} \mathrm{C}$ for $30 \mathrm{sec}$ to elongate including a previous $5 \mathrm{~min}$ of heating at $95^{\circ} \mathrm{C}$ to unfold the cDNA, and a final 7-min extension at $72^{\circ} \mathrm{C}$. The second amplification was performed using $1 \mu \mathrm{l}$ of the first PCR products as templates and the same method as for the first amplification.

Sequence analysis. Aliquots of the first PCR products were separated by electrophoresis using a $1.5 \%$ agarose gel, and DNA bands in the range of $400 \mathrm{bp}$ were purified from the agarose gel using a MinElute gel extraction kit (Qiagen, Hilden, Germany). Purified PCR products were cloned into the TA cloning vector (Invitrogen, San Diego, CA). Randomly picked clones were screened for inserts of $400 \mathrm{bp}$. Positive clones were subjected to cycle sequencing using a BigDye terminator cycle sequence kit (Applied Biosystems, Foster City, CA) according to the manufacturer's recommendations. The sequences were determined by capillary sequencer (Applied Biosystems 310 genetic analyzer). BioEdit (Ibis Therapeutics, Carlsbad, NM) was used for sequence comparison, and JoinSolver [National Institutes of Health, National Institute of Arthritis and Musculosketelal and Skin Diseases (NIAMS) and the Center for Information Technology (CIT)] (28) was used to identify putative Ig-VDJ germline sequences and to clarify the ratio of mutations leading to amino acid replacement to silent mutations (R/S ratio) in the CDR and FR. The IMGT database (Marie-Paule Lefranc, Montpellier, France) was used to confirm the putative Ig-VDJ germline sequences. EMBL Nucleotide Sequence Submissions (European Bioinformatics Institute, Wellcome Trust Genome Campus, Cambridge, UK), and GenBank (National Institutes of Health, Bethesda, Maryland) were also used.

Statistical analysis. The Mann-Whitney U test was used to compare the IgH-CDR3 length of VH between anti-GPI Ab $(+)$ and (-) patients. The two-tailed Fisher exact test was used to determine significant differences in distributions of $\mathrm{JH}$ gene usage. Data are expressed as mean \pm SD. A p value $<0.05$ was considered statistically significant.

\section{Results}

Amplification of VH family genes. Only VH4 genes were identified from all patients by nested PCR (Fig. 1). VH1 to VH5 genes were also identified except for RA3. In contrast, the amplification of VH6 genes was not sufficient for detection.

$R / S$ ratio. After the first $\mathrm{PCR}$, the $\mathrm{VH} 4$ gene products were purified and sequenced. Twenty-seven $(17,8$, and 2 , respectively) individually rearranged $\mathrm{VH} 4$ genes were characterized by sequence analysis in the synovium of anti-GPI Ab (+) RA patients (Table III), and $36(15,19$, and 2 , respectively) were identified in the synovium of anti-GPI Ab (-) individuals (Table III). There was no difference in $\mathrm{R} / \mathrm{S}$ ratio in the CDR of both groups of VH4 clones [70\% (19/27) in anti-GPI Ab (+) and 75\% (27/36) in anti-GPI Ab (-)]; the R/S ratio in the CDR was $>3$, indicating antigen-driven maturation.

VH4 subfamily. Sequences were analyzed by using JoinSolver software to determine the implicated VDJ usage. In the synovium of anti-GPI Ab (+) RA patients, the most frequent VH4 subfamily gene was VH4-59 (12 products) followed by VH4-4 (5 products), VH4-39 (4 products), VH4-31 (3 products), VH4-61 (2 products), and finally, VH4-34 (1 product). In anti-GPI Ab (-) individuals, the dominant detected VH4 subfamily gene was VH4-59 (12 products) followed by VH4-39 (10 products), VH4-31 and VH4-61 (5 products each), and VH4-4 and VH4-34 (2 products each) (Fig. 2a). VH4-39 was therefore relatively less frequent in synovial B cells of antiGPI Ab (+) RA patients, although the statistical significance was not clear.

$J H$ region. In the synovium of anti-GPI Ab (+) RA patients, the most frequent $\mathrm{JH}$ gene was $\mathrm{JH} 4$ (19 products) followed by JH3 (3 products), JH6 (2 products), and JH1, JH2, and JH5 (1 product each). In anti-GPI Ab (-) individuals, the most frequent synovial JH gene was JH5 (10 products) followed by JH6 (9 products), JH3 and JH4 (7 products each), and JH2 ( 3 products) (Fig. 2b). Thus, JH4 usage in synovial B cells of anti-GPI Ab (+) RA patients was 70\%, and showed a significantly higher frequency compared to $19 \%$ usage in anti-GPI Ab (-) individuals ( $\mathrm{p}<0.0001)$.

IgH-CDR3 characteristics: amino acid composition and IgHCDR3 length. There was no statistically significant difference 
Table III. Synovial immunoglobulin VH4 repertoire of anti-GPI Ab (+) and (-) RA patients.

\begin{tabular}{|c|c|c|c|c|c|c|}
\hline & $\mathrm{VH}$ & $\mathrm{DH}$ & $\mathrm{H}-\mathrm{CDR} 3$ & bp & $\mathrm{JH}$ & $\mathrm{R} / \mathrm{S}$ ratio within $\mathrm{CDR}$ \\
\hline \multicolumn{7}{|c|}{ Anti-GPI Ab (+) RA patients } \\
\hline \multirow[t]{17}{*}{ RA1 } & 4-04 & $2-21$ & NMAGDVIGFFDY & 14 & 4 & $2 / 0$ \\
\hline & $4-04$ & $4-23$ & SRNPIDYPLGYFDY & 16 & 4 & $2 / 1$ \\
\hline & $4-04$ & $5-05$ & GYSYGLFDV & 11 & 4 & $\underline{12 / 2}$ \\
\hline & $4-04$ & $6-25$ & QRHRRGDFDI & 12 & 3 & $2 / 0$ \\
\hline & $4-31$ & $3-10$ & EELRRIRGPFFDY & 15 & 4 & $\underline{9 / 3}$ \\
\hline & $4-34$ & $6-06 \mathrm{R}$ & GEQDEHQVSSRFFFYYYIDV & 22 & 6 & $\underline{9 / 2}$ \\
\hline & 4-39 & $2-15$ & QGYCSGGTCQDFDY & 16 & 4 & $\underline{3 / 0}$ \\
\hline & 4-39 & $3-10$ & QGARQWFGEFGAFDY & 17 & 4 & $\underline{6 / 0}$ \\
\hline & $4-59$ & $3-09$ & LSPGGNFDFDL & 13 & 4 & $\underline{6 / 1}$ \\
\hline & $4-59$ & $3-10$ & DGEGGSYYFDY & 13 & 4 & $\underline{9 / 1}$ \\
\hline & $4-59$ & $3-10 R$ & HNNTWHPFDY & 12 & 4 & $\underline{8 / 1}$ \\
\hline & $4-59$ & $3-16 R$ & LPPRGNYRLDS & 13 & 4 & $\underline{5 / 1}$ \\
\hline & $4-59$ & $6-13$ & VPGFSSTWFEVDY & 15 & 4 & $\underline{6 / 2}$ \\
\hline & $4-59$ & $6-13$ & FSGSFYGWFDP & 13 & 5 & $\underline{7 / 0}$ \\
\hline & $4-59$ & IR & VSTQTDY & 9 & 4 & $\underline{5 / 1}$ \\
\hline & $4-59$ & $1-07$ & APPPWLRRVSTGTWL & 17 & 2 & $5 / 3$ \\
\hline & $4-61$ & $2-02 R$ & GRQPDYYYAMDV & 14 & 6 & $8 / 4$ \\
\hline \multirow[t]{8}{*}{ RA2 } & $4-04$ & $5-12 R$ & SPDNRNTLDI & 12 & 3 & $\underline{7 / 2}$ \\
\hline & 4-31 & $3-10$ & GYYYGPGSYHPFET & 16 & 4 & $\underline{3 / 1}$ \\
\hline & $4-31$ & $6-13$ & DRDAAAGRWVDY & 14 & 4 & $\underline{3 / 0}$ \\
\hline & 4-39 & $1-26$ & PVVGARDPAPFDL & 15 & 3 & $4 / 2$ \\
\hline & $4-59$ & $3-03$ & RGGPTEH & 9 & 1 & $\underline{4 / 1}$ \\
\hline & $4-59$ & $3-09$ & DRGQEYGIDS & 12 & 4 & $4 / 2$ \\
\hline & $4-59$ & IR1R & LGQLGDH & 9 & 4 & $\underline{12 / 2}$ \\
\hline & $4-61$ & $1-20$ & VSLLGYKRNDGKYHFDY & 19 & 4 & $\underline{6 / 2}$ \\
\hline \multirow[t]{2}{*}{ RA3 } & 4-39 & $3-10$ & YIRGVRSGGYFDY & 15 & 4 & $4 / 2$ \\
\hline & $4-59$ & $1-26$ & HGVDSGSFYAFDY & 15 & 4 & $\underline{3 / 0}$ \\
\hline \multicolumn{7}{|c|}{ Anti-GPI Ab (-) RA patients } \\
\hline \multirow[t]{15}{*}{ RA4 } & 4-31 & $3-10$ & DHGSGSSYFFSPNYGMDV & 20 & 6 & $\underline{3 / 1}$ \\
\hline & $4-34$ & $5-12$ & GNSGNGYYFYNYMDV & 17 & 6 & $\underline{11 / 3}$ \\
\hline & 4-39 & 2/OR15-2R & FTITLFRGKEGNY & 15 & 4 & $\underline{5 / 0}$ \\
\hline & $4-39$ & 3/OR15-3 & QNGLQSRVDYFDF & 15 & 4 & $\underline{7 / 1}$ \\
\hline & 4-39 & IRR & GGGVNLGSGAFYDE & 16 & 4 & $18 / 7$ \\
\hline & $4-59$ & $1-01$ & GGGFSSNWSLAPFAFDI & 19 & 3 & $3 / 2$ \\
\hline & $4-59$ & $2-15$ & DVDCVGGSCYSSDWFDP & 19 & 5 & $\underline{5 / 1}$ \\
\hline & $4-59$ & $3-22$ & LWGSSGLYGENWFDP & 17 & 5 & $\underline{5 / 1}$ \\
\hline & $4-59$ & 4/OR15-4 & DVTSVQTTMVPAFDY & 17 & 4 & $\underline{9 / 2}$ \\
\hline & $4-59$ & $5-05$ & DIRGYGYGYFDL & 14 & 2 & $\underline{13 / 1}$ \\
\hline & $4-59$ & $6-19$ & DTHTAVPGDDYFES & 16 & 4 & $7 / 3$ \\
\hline & $4-61$ & $1-26$ & ESLKVGSTCFDP & 14 & 5 & $\underline{9 / 3}$ \\
\hline & $4-61$ & $3-10$ & ARPDGSESFYRYLDL & 17 & 2 & $\underline{4 / 1}$ \\
\hline & $4-61$ & $3-10$ & EQTGLRGQNM & 12 & 3 & $\underline{7 / 2}$ \\
\hline & $4-61$ & $4-23$ & EGDYGGSYYYYYMDL & 17 & 6 & $\underline{11 / 0}$ \\
\hline \multirow[t]{6}{*}{ RA5 } & $4-04$ & $2-15$ & AGGGDCSGATCYSYYYGMDV & 22 & 6 & $\underline{5 / 0}$ \\
\hline & 4-31 & $2-21$ & GFGSSVIAMAYYFDY & 17 & 4 & $\underline{3 / 1}$ \\
\hline & $4-31$ & $4-04$ & LHAERALGFWFDP & 15 & 5 & $\underline{17 / 3}$ \\
\hline & 4-31 & 4/OR15-4 & VAPGAMPDDASEI & 15 & 3 & $\underline{8 / 1}$ \\
\hline & $4-34$ & $3-09$ & MANLTGTPGLGI & 14 & 3 & $\underline{7 / 2}$ \\
\hline & $4-39$ & 2/OR15-2R & DYITIFGVAPFDP & 15 & 5 & $\underline{4 / 1}$ \\
\hline
\end{tabular}


Table III. Continued.

\begin{tabular}{|c|c|c|c|c|c|c|}
\hline & $\mathrm{VH}$ & $\mathrm{DH}$ & $\mathrm{H}-\mathrm{CDR} 3$ & bp & $\mathrm{JH}$ & $\mathrm{R} / \mathrm{S}$ ratio within $\mathrm{CDR}$ \\
\hline & $4-39$ & $3-03$ & HVNFEVVIGRWFDH & 16 & 5 & $\underline{13 / 3}$ \\
\hline & V39 & $3-03$ & LGALFGADSYYGMDV & 17 & 6 & $\underline{6 / 1}$ \\
\hline & V39 & $4-23$ & KDYADYEGFAY & 13 & 5 & $\underline{6 / 0}$ \\
\hline & V39 & $5-12$ & YISATMEDF & 11 & 3 & $11 / 2$ \\
\hline & V39 & $6-13$ & DAGYSSSRHPVGFDP & 17 & 5 & $8 / 3$ \\
\hline & V39 & $6-19 R / 3-16$ & HARIGAHYTYGSFRLFDAFDV & 23 & 3 & $\underline{5 / 1}$ \\
\hline & V59 & $3-03$ & DKSGYYTPGGYYYYYGMDV & 21 & 6 & $3 / 2$ \\
\hline & V59 & $3-03$ & APYWSGYVYGLDV & 15 & 6 & $\underline{7 / 1}$ \\
\hline & V59 & $3-10$ & ETYYSASGSYYSGQYYFEY & 21 & 4 & $\underline{6 / 1}$ \\
\hline & V59 & 4/OR15-4 & HGGLYPYYYFAMDV & 16 & 6 & $\underline{5 / 0}$ \\
\hline & V59 & $6-19$ & RTDDYSRGWYWYFDP & 17 & 2 & $\underline{6 / 1}$ \\
\hline & V59 & $6-19 R$ & HAIHRFSTAFPNWFDP & 18 & 5 & $3 / 2$ \\
\hline & V61 & $4-17$ & DASLLYGDYVSWFDP & 17 & 5 & $8 / 5$ \\
\hline \multirow[t]{2}{*}{ RA6 } & V04 & $1-14 \mathrm{R}$ & DPRTVKTMDV & 12 & 6 & $6 / 4$ \\
\hline & V59 & $3-22$ & GPHDTMTNYYGLNAFDI & 19 & 3 & $7 / 4$ \\
\hline
\end{tabular}

The characters of immunoglobulin sequences using VH4 family genes are shown. Bold characters represent based-ionized amino acids ( $\mathrm{R}$, arginine; $\mathrm{H}$, histidine; $\mathrm{K}$, lysine). Underline indicates $\mathrm{R} / \mathrm{S}$ ratio $>3$.

a

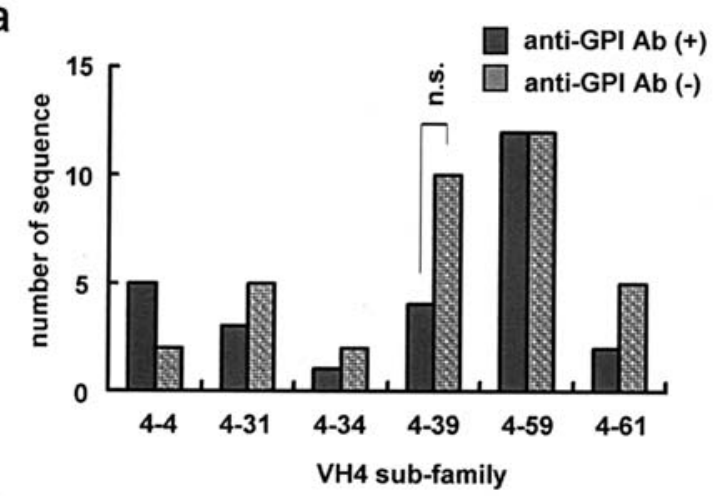

b

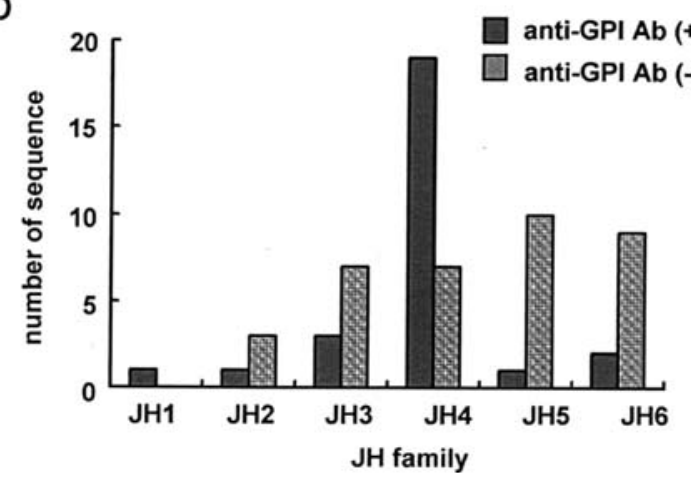

C

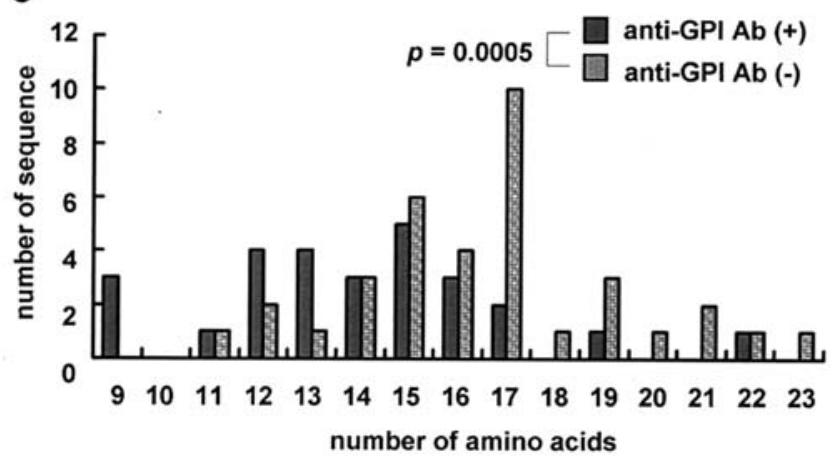

\begin{tabular}{cccc}
\hline $\begin{array}{c}\text { anti-GPI } \\
\mathrm{Ab}\end{array}$ & $\mathrm{JH} 4$ & $\begin{array}{c}\mathrm{JH} 1 / 2 \\
/ 3 / 5 / 6\end{array}$ & $\chi^{2}$ \\
\hline$(+)$ & 19 & 8 & $p<0.0001$ \\
$(-)$ & 7 & 29 & \\
\hline
\end{tabular}

Figure 2. Comparison of synovial VH4 B cells from rheumatoid arthritis (RA) patients with or without anti-glucose-6-phosphate isomerase (GPI) Ab. (a) Usage of VH4 subfamily frequencies of VH4 gene usage in synovial B cells from RA patients are shown. In anti-GPI Ab (+) patients, VH4-59 (12 products), VH4-4 (5 products), VH4-39 (4 products), VH4-31 (3 products), VH4-61 (2 products), and VH4-34 (1 products) were identified. In anti-GPI Ab (-) patients, VH4-59 (12 products), VH4-39 (10 products), VH4-31 and VH4-61 (5 products each), and VH4-4 and VH4-34 (2 products each) were identified. VH4-39 showed a relatively low frequency in synovial B cells of anti-GPI Ab (+) RA patients, although the comparison is statistically not significant. (b) The usage of immunoglobulin heavy chain joining segment (JH) family. The frequencies of JH gene usage of synovial VH4 B cells from RA patients are shown. JH4 (19 products) was the most frequent gene used in anti-GPI Ab (+) RA patients, although this gene was not predominant in anti-GPI Ab (-) individuals (p $<0.0001$ by two-tailed Fisher exact test between JH4 and others). (c) The number of amino acids in the immunoglobulin heavy chain complementarity-determining region 3 (IgH-CDR3). The IgH-CDR3 lengths of VH4 B cells are shown. Lengths varied between 9 and 23 (mean, 15.46 \pm 3.09 ) amino acids. In anti-GPI Ab (+) RA patients, the IgH-CDR3 lengths (14.00 \pm 2.96 amino acids) of synovial VH4 B cells were significantly shorter than those of anti-GPI Ab (-) individuals ( $16.56 \pm 2.75$ amino acids) ( $\mathrm{p}=0.0005$ by Mann-Whitney's $U$ test). 
between the groups in terms of amino acids usage of IgHCDR3, although this region in anti-GPI Ab (+) RA patients was rich in basic-ionized amino acids (arginine, histidine, and lysine) in their near central position, compared to the composition in anti-GPI Ab (-) individuals (Table III).

The IgH-CDR3 amino acid lengths varied from 9 to 23 amino acids (mean, 15.46 \pm 3.09 amino acids). In anti-GPI Ab (+) RA patients, the IgH-CDR3 length of synovial immunoglobulins using VH4 was significantly shorter than the length of those in anti-GPI Ab (-) individuals ( $p=0.0005$, Fig. $2 \mathrm{c}$ ). These findings suggest the prevalence of affinity-matured VH4 $\mathrm{B}$ cells in the synovium of anti-GPI Ab (+) RA patients.

\section{Discussion}

Anti-GPI Ab is frequently detected in patients with aggressive forms of RA $(12,13)$, and its level correlates significantly with extra-articular manifestations such as rheumatoid nodules, rheumatoid vasculitis, and Felty's syndrome (10). We reported previously that serum IgG from anti-GPI Ab (+) RA patients preferentially attached to the articular surface of the metacarpophalangeal joints of the monkey, inducing recruitment of granulocytes and mononuclear cells into the synovium (29). These results indicated that human serum immunoglobulins from RA patients include autoantibodies to specific protein(s) expressed in the joint cavity. Furthermore, human GPI protein is expressed on the cartilage and synovial surface in RA (7) and anti-GPI Ab is present in the synovial fluid, suggesting that the local production of such autoantibodies might be associated with arthritis. To address this hypothesis, we focused on the synovial B cells of anti-GPI Ab (+) patients.

In the present study, VH4 genes were detected in the synovium of all patients with RA. In some autoimmune diseases such as systemic lupus erythematosus (SLE) $(30,31)$, VH4 genes are overrepresented in peripheral B cells (18), although negative selection of $\mathrm{VH} 4$ genes occurs in healthy individuals $(19,20)$. These observations implicate VH4 genes as a self-reactive gene family. The frequency of VH4 genes in peripheral B cells from RA patients was not different from that of healthy individuals (32), however VH4 genes were highly expressed in the rheumatoid synovial B cells $(21,22)$. In addition, antigen-driven immune maturation of $\mathrm{B}$ cells is characterized by an R/S ratio $>3$ within the CDR (33). Our study demonstrated that $\mathrm{VH} 4(+)$ synovial B cells in patients with RA are affinity-matured, because immunoglobulins with a high $\mathrm{R} / \mathrm{S}$ ratio were dominant.

A skewed VH4 subfamily in RA synovium was not identified in this study, but when we compared anti-GPI Ab (+) with (-) patients, VH4 subfamily usages of synovial B cells from anti-GPI Ab (+) RA patients were less frequent for VH4-39. In peripheral blood of SLE, VH4-34 (V4.21) was overexpressed and correlated with some autoantibodies $(30,31)$, but no specific subfamily repertoire has been identified in the synovium of RA patients. We do not know whether these skewed VH4 subfamilies are related to arthritogenicity, however, there are reports that some autoantibodies with VH4-34 (V4.21) segments are related to the pathogenicity of SLE $(34,35)$. Since anti-GPI Ab is a candidate arthritogenic antibody, it would be interesting to identify the skewed VH4 subfamilies by increasing numbers of the sequence.
Our sequence analysis noted that synovial IgH-CDR3 from anti-GPI Ab (+) RA patients was enriched in basic-ionized amino acids. The ionized side-chains of arginine in the CDRs contribute to higher binding affinity for some antigens such as DNA, cardiolipin (36,37), and TAG72 (38). A previous study found that arginine in IgH-CDR3 of human and murine anti-dsDNA was most likely to be generated during V-D-J rearrangement in B cells, and the higher frequency of arginine in the IgH-CDR might similarly be due to the clonal expansion of $\mathrm{B}$ cells (38). In addition, the precise location of arginine is important for the binding (37).

IgH-CDR3 length and amino acid composition is the major contributor to antigen specificity and affinity (39-41). Matured immunoglobulins have shorter CDR3s than non-matured ones in both mice and humans $(42,43)$. In the present anti-GPI Ab (+) RA patients, the CDR3 length of synovial immunoglobulins using VH4 was significantly shorter and the JH4 usage was significantly higher than those of anti-GPI Ab (-) individuals. These data support the notion that synovial B cells of anti-GPI $\mathrm{Ab}(+)$ patients are affinity-matured with higher affinity to a particular antigen.

In conclusion, our findings on synovial B cells in RA patients positive for anti-GPI Ab clearly demonstrated a high frequency of VH4-JH4 subfamily genes rich in basic amino acids and shorter CDR3 length, indicating affinity-matured B cells, reactive to autoantigens such as GPI. Future studies using anti-GPI Ab-producing B cell hybridomas should shed light on the functional role of anti-GPI Ab in the pathogenesis of RA.

\section{Acknowledgements}

This study was supported in part by the Japanese Ministry of Science and Culture (IM, TS) and PRESTO, Japan Science and Technology Agency (IM). IM is also a recipient of a fellowship from the Japan Intractable Diseases Research Foundation, Uehara Memorial Foundation, and Japan Rheumatoid Foundation.

\section{References}

1. Firestein GS: Evolving concepts of rheumatoid arthritis. Nature 423: 356-361, 2003

2. Silverman GJ and Carson DA: Roles of B cells in rheumatoid arthritis. Arthritis Res Ther 5 (suppl 4): S1-S6, 2003.

3. Leandro MJ, Edwards JC and Cambridge G: Clinical outcome in 22 patients with rheumatoid arthritis treated with B lymphocyte depletion. Ann Rheum Dis 61: 883-888, 2002.

4. Higashida J, Wun T, Schmidt S, et al: Safety and efficacy of rituximab in patients with rheumatoid arthritis refractory to disease modifying antirheumatic drugs and anti-tumor necrosis factor-alpha treatment. J Rheumatol 32: 2109-2115, 2005.

5. Matsumoto I, Staub A, Benoist C, et al: Arthritis provoked by linked $\mathrm{T}$ and $\mathrm{B}$ cell recognition of a glycolytic enzyme. Science 286: 1732-1735, 1999.

6. Benoist $\mathrm{C}$ and Mathis D: A revival of the $\mathrm{B}$ cell paradigm for rheumatoid arthritis pathogenesis? Arthritis Res 2: 90-94, 2000 .

7. Matsumoto I, Maccioni M, Lee DM, et al: How antibodies to a ubiquitous cytoplasmic enzyme may provoke joint-specific autoimmune disease. Nat Immunol 3: 360-365, 2002.

8. Kouskoff V, Korganow AS, Duchatelle V, et al: Organ-specific disease provoked by systemic autoimmunity. Cell 87: 811-822, 1996.

9. Schaller M, Burton DR and Ditzel H: Autoantibodies to GPI in rheumatoid arthritis: linkage between an animal model and human disease. Nat Immunol 2: 746-753, 2001. 
10. van Gaalen FA, Toes RE, Ditzel HJ, et al: Association of autoantibodies to glucose-6-phosphate isomerase with extraarticular complications in rheumatoid arthritis. Arthritis Rheum 50: 395-399, 2004

11. Jouen F, Vittecoq O, Leguillou F, et al: Diagnostic and prognostic values of anti glucose-6-phosphate isomerase antibodies in community-recruited patients with very early arthritis. Clin Exp Immunol 137: 606-611, 2004.

12. Matsumoto I, Lee DM, Goldbach-Mansky R, et al: Low prevalence of antibodies to glucose-6-phosphate isomerase in patients with rheumatoid arthritis and a spectrum of other chronic autoimmune disorders. Arthritis Rheum 48: 944-954, 2003.

13. Hayashi T, Matsumoto I, Muraki Y, et al: Clinical characteristics of anti-glucose-6-phosphate isomerase antibody-positive Japanese patients with rheumatoid arthritis. Mod Rheumatol 15: 258-263, 2005.

14. Schaller M, Stohl W, Tan SM, et al: Raised levels of antiglucose-6-phosphate isomerase IgG in serum and synovial fluid from patients with inflammatory arthritis. Ann Rheum Dis 64: 743-749, 2005.

15. Cha HS, Kim TJ, Kim JY, et al: Autoantibodies to glucose-6phosphate isomerase are elevated in the synovial fluid of rheumatoid arthritis patients. Scand J Rheumatol 33: 179-184, 2004.

16. Kim JY, Lee MH, Jung KI, et al: Detection of antibodies against glucose 6-phosphate isomerase in synovial fluid of rheumatoid arthritis using surface plasmon resonance (BIAcore). Exp Mol Med 35: 310-316, 2003.

17. Matsuda F, Ishii K, Bourvagnet P, et al: The complete nucleotide sequence of the human immunoglobulin heavy chain variable region locus. J Exp Med 188: 2151-2162, 1998.

18. Pascual V and Capra JD: VH4-21, a human VH gene segment overrepresented in the autoimmune repertoire. Arthritis Rheum 35: 11-18, 1992.

19. Brezinschek HP, Brezinschek RI and Lipsky PE: Analysis of the heavy chain repertoire of human peripheral B cells using single-cell polymerase chain reaction. J Immunol 155: 190-202, 1995.

20. Pugh-Bernard AE, Silverman GJ, Cappione AJ, et al: Regulation of inherently autoreactive VH4-34 B cells in the maintenance of human B cell tolerance. J Clin Invest 108: 1061-1070, 2001.

21. Kim HJ, Krenn V, Steinhauser G, et al: Plasma cell development in synovial germinal centers in patients with rheumatoid and reactive arthritis. J Immunol 162: 3053-3062, 1999.

22. Voswinkel J, Trümper L, Carbon G, et al: Evidence for a selected humoral immune response encoded by VH4 family genes in the synovial membrane of a patient with rheumatoid arthritis. Clin Exp Immunol 106: 5-12, 1996.

23. Brown CM, Longhurst C, Haynes $\mathrm{G}$, et al: Immunoglobulin heavy chain variable region gene utilization by $\mathrm{B}$ cell hybridomas derived from rheumatoid synovial tissue. Clin Exp Immunol 89: 230-238, 1992.

24. Gause A, Gundlach K, Carbon G, et al: Analysis of VH gene rearrangements from synovial $B$ cells of patients with rheumatoid arthritis reveals infiltration of the synovial membrane by memory B cells. Rheumatol Int 17: 145-150, 1997.

25. Voswinkel J, Weisgerber K, Pfreundschuh M, et al: The B lymphocyte in rheumatoid arthritis: recirculation of B lymphocytes between different joints and blood. Autoimmunity 31: 25-34, 1999.
26. Schröder AE, Greiner A, Seyfert C, et al: Differentiation of B cells in the non-lymphoid tissue of the synovial membrane of patients with rheumatoid arthritis. Proc Natl Acad Sci USA 93: 221-225, 1996.

27. Arnett FC, Edworthy SM, Bloch DA, et al: The American Rheumatism Association 1987 revised criteria for the classification of rheumatoid arthritis. Arthritis Rheum 31: 315-324, 1988.

28. Souto-Carneiro MM, Longo NS, Russ DE, et al: Characterization of the human Ig heavy chain antigen binding complementarity determining region 3 using a newly developed software algorithm, JOINSOLVER. J Immunol 172: 6790-6802, 2004.

29. Suzuki T, Muraki Y, Yasukochi T, et al: Immunoglobulin G from anti-glucose-6-phosphate isomerase antibodies positive patient with rheumatoid arthritis induces synovitis in cynomolgus monkeys. Autoimmun Rev 4: 475-478, 2005.

30. van Vollenhoven RF, Bieber MM, Powell MJ, et al: VH4-34 encoded antibodies in systemic lupus erythematosus: a specific diagnostic marker that correlates with clinical disease characteristics. J Rheumatol 26: 1727-1733, 1999.

31. Bhat NM, Lee LM, van Vollenhoven RF, et al: VH4-34 encoded antibody in systemic lupus erythematosus: effect of isotype. J Rheumatol 29: 2114-2121, 2002.

32. Huang SC, Jiang R, Hufnagle WO, et al: VH usage and somatic hypermutation in peripheral blood $\mathrm{B}$ cells of patients with rheumatoid arthritis (RA). Clin Exp Immunol 112: 516-527, 1998.

33. Chang B and Casali P: The CDR1 sequences of a major proportion of human germline Ig VH genes are inherently susceptible to amino acid replacement. Immunol Today 15: 367-373, 1994.

34. Waisman A, Shoenfeld Y, Blank M, et al: The pathogenic human monoclonal anti-DNA that induces experimental systemic lupus erythematosus in mice is encoded by a VH4 gene segment. Int Immunol 7: 689-696, 1995.

35. Denomme GA, Mahmoudi M, Cairns E, et al: Immunoglobulin V region sequences of two human antiplatelet monoclonal autoantibodies derived from B cells of normal origin. J Autoimmun 7: 521-535, 1994.

36. Rahman A: Autoantibodies, lupus and the science of sabotage. Rheumatology 43: 1326-1336, 2004.

37. Giles I, Lambrianides N, Latchman D, et al: The critical role of arginine residues in the binding of human monoclonal antibodies to cardiolipin. Arthritis Res Ther 7: 47-56, 2005.

38. Xiang J, Chen Z, Delbaere LT, et al: Differences in antigenbinding affinity caused by a single amino acid substitution in the variable region of the heavy chain. Immunol Cell Biol 71: 239-247, 1993.

39. Rosner K, Winter DB, Tarone RE, et al: Third complementaritydetermining region of mutated $\mathrm{VH}$ immunoglobulin genes contains shorter V, D, J, P, and N components than non-mutated genes. Immunology 103: 179-187, 2001.

40. Xue W, Luo S, Adler WH, et al: Immunoglobulin heavy chain junctional diversity in young and aged humans. Hum Immunol 57: 80-92, 1997.

41. Wang X and Stollar D: Immunoglobulin VH gene expression in human aging. Clin Immunol 93: 132-142, 1999.

42. McHeyzer-Williams MG, McLean MJ, Lalor PA, et al: Antigendriven B cell differentiation in vivo. J Exp Med 178: 295-307, 1993.

43. Brezinschek HP, Foster SJ, Dorner T, et al: Pairing of variable heavy and variable $\mathrm{k}$ chains in individual naïve and memory $\mathrm{B}$ cells. J Immunol 160: 4762-4767, 1998. 